\title{
Erratum to: Enhanced osseous integration of human trabecular allografts following surface modification with bioactive lipids
}

Tiffany Wang ${ }^{1} \cdot$ Jack Krieger $^{1}$ - Cynthia Huang ${ }^{2} \cdot$ Anusuya Das $^{2} \cdot$ Molly Dickinson $^{2}$. Michael P. Francis ${ }^{3} \cdot$ Roy Ogle $^{4} \cdot$ Edward Botchwey $^{1}$

Published online: 16 May 2016

(C) Controlled Release Society 2016

Erratum to: Drug Deliv. and Transl. Res. (2016) 6:96-104

DOI 10.1007/s13346-015-0244-0

The authors regret that Molly Dickinson was inadvertently omitted as a coauthor of the article. She has been added as shown in this erratum.

The online version of the original article can be found under doi:10.1007/ s13346-015-0244-0.

Edward Botchwey

edward.botchwey@bme.gatech.edu

1 Wallace H. Coulter Department of Biomedical Engineering, Georgia Institute of Technology and Emory University, 315 Ferst Drive Rm 1311, Atlanta, GA 30332, USA

2 Department of Biomedical Engineering, University of Virginia, Charlottesville, VA 22903, USA

3 LifeNet Health, Virginia Beach, VA 23453, USA

4 School of Medical Diagnostic and Translational Science, Old Dominion University, Norfolk, VA 23529, USA 